\title{
A LEI No 10639/03: ENTRE PRÁTICAS E POLÍTICAS CURRICULARES
}

THE LAW No 10639/03: BETWEEN CURRICULUM POLICIES AND PRACTICES

Rosemeire dos Santos ${ }^{1}$

\begin{abstract}
RESUMO: O presente artigo pretende tecer algumas considerações sobre a Lei n010639/03, que está próxima de completar oito anos de sua promulgação e cuja implementação ainda não produziu os resultados esperados, levantando-se alguns pontos de dificuldade na sua efetivação. Utilizando parte de um projeto, ainda em desenvolvimento, procuraremos fazer uma reflexão justamente sobre as dificuldades de realização da Lei. Dessa reflexão nasceram algumas indagações que buscaremos discutir ao longo do texto, a saber: como os professores estão se apropriando desta lei? Quais são as possíveis resistências enfrentadas? Chegando a mais indagações do que respostas esse artigo procura mostrar que uma lei não é o bastante no intuito de se corrigir distorções históricas sofridas por negros e afrodescendentes, é preciso acrescer a ela um intenso trabalho de formação dos professores, que realizaram o trabalho junto aos alunos, suscitando primeiro neles o interesse e significação para que se considere legítimo mudar sua prática ou que se crie uma nova.
\end{abstract}

Palavras-Chave: Currículo. Lei no 10639. Livro didático. Apropriação de professores. Afrodescentes.

\begin{abstract}
The present article intends to discuss some considerations about the Law no 10639/03, which is approaching its 8th year from its publication and whose insertion hasn 't produced the expected results, as of yet, pointing out a few points of difficulty for its effectuation. Using part of a project, still being developed, we shall do a study on the difficulties for the implementation of the law. From this study some questions have arid, and ones we shall try to answer along the text, such as: how are the teachers taking hold of this Law? What are the probable resistances to be faced? Getting to more queries than answers, this article tries to show that a law is not quite enough to correct historical distortions suffered by blacks and afrodescendents. It is necessary to add an intensive work with the teachers who have interacted directly with the students, so that these teachers acquire the interest and the will to think legit the changing of its practice, or to consider the making of another.
\end{abstract}

Keywords: Curricula. Law n. ${ }^{\circ}$ 10639. Textbooks. Appropriation of teachers.

\footnotetext{
${ }^{1}$ Professora de História de Ensino Fundamental e Ensino Médio do Colégio de Aplicação de Londrina, órgão suplementar da Universidade Estadual de Londrina.
} 


\section{Introdução}

Resultante de um longo processo de lutas e reivindicações do movimento negro brasileiro, a Lei no 10639/03², sancionada em dezembro de 2003, alterou a Lei de Diretrizes e Bases (LDB) n 9394 de 1996, nos incisos 26, 26A e 79, tornando obrigatório o ensino de história e cultura africana no sistema de educacão básica, especialmente nas disciplinas de história, português e artes. Em vigor desde então, a Lei busca a inserir novos conteúdos, visando à correção histórica de um currículo oficial que manteve silêncio sobre a cultura e as raízes ancestrais de parte considerável da população brasileira. A proposta é a de promover à aquisição de um conhecimento isento de preconceitos e distorções, gerando, a médio e longo prazo, uma sociedade aberta, no início a discussão, e tolerante as pluralidades étnicas raciais características do Brasil. Podemos inferir, a partir do texto da Lei e suas diretrizes, que as novas abordagens propostas devem colocar outras questões além daquelas costumeiramente relacionadas ao regime escravocrata, dito de outra forma, os estudos sobre o negro e sua cultura voltar-se-ão para a compreensão de toda a sua dimensão histórica e não apenas das relações de trabalho. Com isso, os formuladores desse projeto acreditam ser possível desencadear um processo, que aliado a outras políticas afirmativas, possa levar ao resgate da identidade e autoestima dos integrantes da comunidade afrodescendente brasileira, suscitando-Ihes um sentimento de pertencimento a um povo, de cujo passado histórico possam sentir orgulho e não piedade. Em síntese, um país no qual quase metade da população é negra ou descendente, a Lei é uma tentativa de instaurar um diálogo acerca dos preconceitos raciais

\footnotetext{
2 "Art. 10 A Lei no 9.394, de 20 de dezembro de 1996, passa a vigorar acrescida dos seguintes arts. 26-A, 79-A e 79-B:"Art. 26-A. Nos estabelecimentos de ensino fundamental e médio, oficiais e particulares, torna-se obrigatório o ensino sobre História e Cultura AfroBrasileira. § 100 conteúdo programático a que se refere o caput deste artigo incluirá o estudo da História da África e dos Africanos, a luta dos negros no Brasil, a cultura negra brasileira e o negro na formação da sociedade nacional, resgatando a contribuição do povo negro nas áreas social, econômica e política pertinentes à História do Brasil. § 20 Os conteúdos referentes à História e Cultura Afro-Brasileira serão ministrados no âmbito de todo o currículo escolar, em especial nas áreas de Educação Artística e de Literatura e História Brasileiras. Art. 79-B. O calendário escolar incluirá o dia 20 de novembro como 'Dia Nacional da Consciência Negra'. Art. 20 Esta Lei entra em vigor na data de sua publicação"
} 
relacionados aos negros e descedentes, partindo da reparação curricular. Mas, ao mesmo tempo em que busca a implementação de um currículo que reconheça os valores da história e da cultura africana objetiva, a partir da construção de um conhecimento histórico mais profundo, despertar debates entorno de questões relacionadas a omissão e negação aos negros de direitos legalmente constituídos, e a forma como ao longo de aproximadamente cinco séculos os negros têm sido (re) apresentados na história oficial brasileira.

\section{As Práticas Curriculares e a Lei 10639/03}

As políticas curriculares oficiais não costumam ser um reflexo do pensamento de docentes e demais pessoas ligadas ao cotidiano escolar, pois essas pessoas raramente são chamadas a discutirem as novas propostas governamentais. Elaboradas longe do chão de sala de aula, elas trazem consigo um conjunto de prescrições escritas a serem implantadas pelas escolas, o que nem sempre acontece. Nesse sentido Goodson chama a atenção para o fato de o currículo escrito ser apenas um documento legal, no qual as intenções políticas estão colocadas em termos oficiais e, embora sirva de fonte documental para o entendimento da estrutura institucional da escola ele está sujeito a mudanças:

O currículo escrito não passa de um testemunho visível, público e sujeito a mudanças, uma lógica que se escolhe para, mediante sua retórica, legitimar uma escolarização. Como tal, o currículo escrito promulga e justifica determinadas intenções básicas de escolarização, à medida que vão sendo operacionalizadas em estruturas e instituições. Tomemos esta convenção comum, que é a matéria escolar, num currículo pré-ativo: enquanto o currículo escrito estabelece a lógica e a retórica da matéria, o que aparece é apenas o aspecto mais tangível, abrangendo padronização de recursos, meios financeiros, exames, iniciativas correlatas e interesses de carreira. Nesta simbiose, é como se o currículo escrito oferecesse um roteiro para a retórica legitimadora da escolarização, à medida que esta mesma retórica fosse promovida através de padrões para a alocação de recursos, atribuição de status e classificação profissional. Em síntese, o currículo escrito nos proporciona um testemunho, uma fonte 
documental, um mapa do terreno sujeito a modificações; constitui também um dos melhores roteiros oficiais para a estrutura institucionalizada da escolarização (GOODSON, 2005, p. 21)

Esse currículo documental, descrito por Goodson, é apresentado aos educadores, e esses inúmeras vezes são convocados a se enquadrarem nessa lógica, a fim de legitimá-la e tornar o currículo pré ativo em ativo. No entanto, essas frequentes as imposições curriculares, não são imunes as apropriações e ressignificações aplicadas a esses currículos pelos educadores, para que estes sejam aptos a atender às necessidades específicas das diferentes realidades escolares. Nesse jogo de forças os lados buscam alternativas capazes de validarem seus pressupostos e tornálos uma realidade. Assim, se por um lado há um currículo oficial normatizado e alvo das resistências dos professores, por outro os governos dispõem de um meio, com status de oficial e menor rejeição junto a comunidade escolar, do qual os gestores públicos se utilizam quando querem tornar ativo um currículo que está sendo proposto, especialmente, quando as mudanças propostas estão no âmbito dos conteúdos, trata-se de um instrumento complementar a todo processo oficial, o livro didático. Alterações via conteúdo encontram nos livros didáticos seu principal e mais importante meio de veiculação, algumas recomendações legais e pareceres com informação e orientações não chegam aos professores sem que lhes causem recusa, mas os livros didáticos instrumentalizam novos conteúdos disponibilizando-os a professores e alunos e não enfrentam os mesmos problemas de resistência e rejeição. Uma possibilidade de explicação para isso encontra-se no fato de livros serem escolhidos pelos professores, embora sejam previamente selecionados pelas instâncias governamentais responsáveis elaboração dos catálogos do PNLD (Plano Nacional do Livro Didático), a decisão final sobre a adoção ou não de um determinado livro cabe ao professor.

Como envolve questões mercadológicas a adequação dos livros didáticos às propostas de mudanças curriculares costuma ser rápida. Tal fato pôde ser observado após 2003 quando a Lei no 10639 foi sancionada, como suas diretrizes curriculares somente foram apresentadas em outubro 
de 2004, os guias de livros didáticos de 2004 não traziam coleções com as alterações, pois a lei entrou em vigor entre os períodos de 2004 e 2007, segundo (MOREIRA e PEREIRA, 2009, p.71) para o PNLD de 2008, as coleções já traziam os conteúdos relativos à nova proposta. Nessas coleções de livros didáticos encontramos de forma concomitante a manifestação do currículo oficial e as primeiras apropriações e ressignificações das proposições da Lei, pois os diferentes autores abordaram os conteúdos da maneira que acreditavam ser a mais interessante para o entendimento da história e cultura africana. Integrados ao sistema educacional brasileiro a décadas, os livros didáticos, nesse caso, foram o contato inicial de diversos professores com os conteúdos dessa nova proposta curricular, já que os materiais foram sendo, lentamente, disponibilizados após a sanção da lei, obras como A História da Africa patrocinada pelo Unicef chegaram ao domínio público apenas em 2010. Porém, historicamente os livros didáticos têm sido criticados por muitos estudiosos como instrumento governamental dogmatizador do processo de ensino e aprendizagem, ou pelo menos como uma tentativa de sê-lo, pois trazem consigo o passo a passo do "bom ensinar" e, supostamente do "bom aprender", retirando de professores e alunos, por vezes, sua autonomia. Assim, colocados no âmbito dos livros textos, os conteúdos relacionados a história da África quando chegaram aos professores já haviam passado pelo filtro governamental, sendo previamente selecionados.

Dada sua trajetória histórica e por serem uma manifestação pública das políticas educacionais, os livros didáticos se transformaram, nos últimos anos, em objetos de inúmeras pesquisas e estudos por parte de pesquisadores de diferentes áreas relacionadas a educação. Esses estudos mostram que, a adoção do livro didático não limita o campo de atuação dos professores e, certamente não os impede de desenvolver estratégias de "resistência" a esses materiais quando julgam ser pertinente, sendo, por exemplo, comum a adoção de outros livros e materiais variados e frequentes o uso dos livros didáticos como complemento a outros com os quais há maior identificação. Dentro dessa conjuntura, os livros podem, até, se tonarem ferramentas importantes em sala de aula, seja para refutar os 
conceitos ali apresentados, seja para ratificá-los. As realidades de sala de aula aliadas a formação do professor funcionam como determinantes sobre quais decisões tomar quanto a esse material.

Novas interpretações têm sido propostas quando se pensa o papel do livro didático, abrindo-se outras possibilidades interpretativas e se levantando diferentes hipóteses sobre a importância desses livros, para Munakata por exemplo, eles estão deixando de serem vistos apenas como material de segunda categoria e:

[...] constituindo-se em poderosos "instrumentos culturais de primeira ordem", os livros didáticos, ao lado de outros meios de comunicação de massa, constroem uma base para a criação de um consenso cultural mínimo que assegure a vertebração social, a "integração da comunidade". (MUNAKATA, 2007, p. 138)

A qualificação do livro didático como meio de comunicação de massa, não é uma novidade, para a efetivação das propostas da lei no 10639/03 esse é um meio que pode ser muito útil, porque para que a lei adquira legitimidade é imprescindível a sua aceitação por parte daqueles que são seu público alvo, nesse sentido contar com um instrumento que atinja o maior contingente possível de forma direta pode facilitar e viabilização das propostas e criar o que Munakata está chamando de "consenso cultural mínimo", não estamos com isso desconsiderando os demais atores desse processo, nem atribuindo papel principal ao livro didático e sim considerando que ele pode ter relevância na construção de um novo olhar sobre a cultura africana ou na solidificação de conceitos equivocados que permeiam a sociedade.

A presença de um currículo escrito ou pré-ativo, seja concebido por novas leis ou já há muito presente nos livro didático, não implica na execução total e irrestrita do mesmo, e, ainda que essa execução ocorra, ela normalmente se faz de forma parcial, adaptada e ressignificada, pois uma gama variada de manipulações e arranjos acontece no intuito de adaptá-lo às diferentes realidades e idiossincrasias. Em se tratando da lei n010639/03 os procedimentos adotados pelos educadores são semelhantes aos que se dão em outras situações. A Lei é um currículo oficial e prescrito, 
portanto passível de adaptações e negações, e traz consigo o caráter impositivo das políticas curriculares, que como já dito antes não são o resultado de um prévio debate junto aos educadores e a posteriori não primam por um diálogo explicativo e/ou uma consistente formação continuada acerca daquilo que está sendo proposto. Como sua efetivação não está sujeita a seu controle, mas é dependente desse universo amplo de pessoas e realidades, deixadas às margens do processo de construção, a sua implementação pode apresentar alguns problemas. Para começar as multiplicidades de interpretações e apropriações são inevitáveis e observar como essas interpretações acontecem é complicado, a não ser em pequenas amostras. Não há como esquecer que o cotidiano escolar traz consigo práticas que não se passíveis de quantificação ou delimitações, principalmente, porque, muitas vezes, elas surgem para atenderem as especificidades de um momento único, que não se repete da mesma maneira. Em síntese, não é possível afirmar, em especial nesse estágio do projeto, quais têm sido os mecanismos utilizados na aceitação ou ignorância da legislação, ou ainda quais interpretações e significados Ihe são atribuídos no dia a dia escolar, estamos, portanto, trabalhando com hipóteses.

As hipóteses levantadas sobre como a Lei é apropriada pelos agentes escolares, têm que considerar que primeiro: o espaço da escola é notadamente social e, por conseguinte, político, a heterogeneidade se encontra na sua própria gênese e ao abrigar múltiplas realidades produz discursos múltiplos. Segundo, a escola não se separa da realidade na qual está inserida e traz para seu interior características determinantes de seu externo. Se na sociedade uma Lei precisa não apenas ser sancionada para ser praticada, precisa ser tida como justa e legítima para ganhar aceitação, era de se esperar que, para a instituição escolar, o simples ato de criação e promulgação da Lei 10639 não bastasse para sua aceitação ampla e irrestrita. Quanto a isso, estamos de acordo com Chervel (1990) que em seu trabalho sobre a história das disciplinas, coloca-nos a questão de que uma lei por si só não seria o suficiente para mudar ou inserir uma nova prática escolar, sendo necessário algo mais. Seria importante, mais que isso necessário, que ela atendesse a alguma finalidade real do universo escolar, 
que não estivesse destinada apenas a satisfação dos poderes públicos, ou seja, para aqueles que transformam a teoria em prática tem que haver significação naquilo que está sendo proposto, assim a proposta adquire status de prática. Não havendo, na concepção dos educadores, relevância suficiente capaz de justificar uma mudança de paradigma, as políticas educacionais se diluem num vazio, que se inicia e se finda em si mesmo.

Quando as resistências a Lei 10639 surgem não podemos esperar que haja um consenso de que embora a lei seja uma questão curricular, ela é também uma questão sociocultural, uma vez não dispormos de meios que nos permita afirmar ter havido as discussões necessárias para esse entendimento. A história nos permite inferir que apesar da aparente serenidade racial brasileira, esse é um assunto que quando seriamente discutido, com todos os integrantes da comunidade escolar, pode suscitar mal estar, principalmente porque parcela da sociedade brasileira não reconhece a existência de preconceito racial no país. Sendo assim, não é o bastante criar uma lei quando ela parece não vir de encontro as necessidades reais.

As propostas da lei se aplicam a todas as disciplinas do currículo escolar, mas principalmente a disciplinas de português, arte e história. A esta última, em especial, cabe o papel de rediscutir o tratamento dispensado a história e cultura africanas e afrodescente no Brasil. Ao longo de décadas, a história escolar brasileira tratou parcialmente da história africana, criou-se um modelo no qual ela se inicia com as Grandes Navegações, mais especificamente, ela tem seu marco inaugural com a economia canavieira e por consequência a adoção do trabalho escravo e se encerra com a abolição. Após o final século XIX, a história como disciplina escolar diluiu a história negra no Brasil nos mitos das três raças e da democracia racial, discussões e questionamentos sobre preconceitos e injustiças foram banidas dessas produções, e os livros passaram a apresentar o negro como um elemento estrangeiro que se incorporou a cultura nacional, de origem europeia, para qual ele contribuiu com um riquíssimo folclore. Sobre isso Fernandes informa que: 
Apesar da renovação teórico-metodológica da História nos últimos anos, o conteúdo programático dessa disciplina na escola fundamental tem primado por uma visão monocultural e eurocêntrica de nosso passado. Inicia- se o estudo da chamada "História do Brasil" a partir da chegada dos portugueses, ignorando-se a presença indígena anterior ao processo de conquista e colonização. Exalta-se o papel do colonizador português como desbravador e único responsável pela ocupação de nosso território. Oculta-se, no entanto, o genocídio e etnocídio praticados contra as populações indígenas no Brasil: eram cerca de 5 milhões à época do chamado "descobrimento", hoje não passam de 350 mil índios. Os africanos, que aportaram em nosso território na condição de escravos, são vistos como mercadoria e objeto nas mãos de seus proprietários. Nega-se ao negro a participação na construção da história e da cultura brasileiras, embora tenha sido ele a mão-de-obra predominante na produção da riqueza nacional, trabalhando na cultura canavieira, na extração aurífera, no desenvolvimento da pecuária e no cultivo do café, em diferentes momentos de nosso processo histórico. (FERNANDES, 2005, p.380)

O autor continua destacando o fato de que a cultura das minorias é vista de forma "folclorizada e pitoresca". Argumenta ainda que nos currículos e manuais didáticos:

[...] silenciam e chegam até a omitir a condição de sujeitos históricos às populações negras e ameríndias têm contribuído para elevar os índices de evasão e repetência de crianças provenientes dos estratos sociais mais pobres. A grande maioria adentra nos quadros escolares e sai precocemente sem concluir seus estudos no ensino fundamental por não se identificarem com uma escola moldada ainda nos padrões eurocêntricos, que não valoriza a diversidade étnico-cultural de nossa formação. (FERNANDES, 2005, 380-1)

Esse padrão de ensino não é representativo para parte importante dos estudantes para os quais, mesmo concluindo o ensino fundamental, o currículo ensinado pode não adquiri significado, já que não se veem, a si e a sua história, contemplados nesses currículos. Romper com esse padrão, tentando intervir ou mudar a prática dos professores, é bem mais difícil do que as se pode supor, não bastando uma lei para fazê-lo. Seria necessário, acreditamos, para o entendimento dessa dificuldade, pesquisar quais fatores determina a apropriação do professor em relação aos diferentes conteúdos, quais são os saberes fundamentais em sua formação, seus 
saberes experienciais, sua memória escolar, representações que ele traz consigo do que seria um bom professor, fatores associados ao sexo, idade, etnia e religião. De acordo com Tardif, esse conjunto de fatores é decisivo na ação dos professores em sala porque eles "utilizam constantemente seus conhecimentos pessoais" ao ensinarem (2000, p.214). Alguns professores podem resistir a trabalhar os novos conteúdos relacionados à lei por julgálos desnecessários, pois, para tais professores, a noção de uma sociedade racialmente igualitária parece estar profundamente arraigada, o que pode ser fruto de seus saberes construídos no decorrer do tempo esses para Tardif são saberes existenciais, uma vez que:

Um professor não pensa somente com a cabeça, mas com a vida, com o que foi, com o que viveu, com aquilo que acumulou em termos de experiência de vida, em termos de lastro de certezas. Em suma, ele pensa a partir de sua história de vida e não somente intelectual, no sentido rigoroso do termo, mas também emocional, afetiva, pessoal e interpessoal. Desse ponto de vista, convém ultrapassar a visão epistemológica canônica do sujeito e do objeto, se quisermos compreender os saberes do professor. (TARDIF, 2000, p.235)

Temos que considerar, também, a existência de professores que não dispõem desses saberes, nesse caso como trabalhar esse novo currículo? Não podemos afirmar quais tipos de formação foram ministradas aos professores no intuito de prepará-los devidamente para colocarem em prática as propostas da legislação, havendo, inclusive, a possibilidade de muitos professores não terem tido acesso a formação alguma nos conteúdos tocante as propostas da legislação. Não estamos preocupados em culpados, e sim em entender quais motivos podem estar atuando como obstáculos ou dificultador da implementação da lei n¹0639/03.

Para levantarmos estas possíveis razões, nos baseamos em Luiz Carlos Paixão da Rocha, que em um artigo sobre as dificuldades de efetivação da Lei, no estado do Paraná, realizou uma pesquisa junto a uma escola estadual de Curitiba, buscando entender porque era tão complicado efetivar as propostas da Lei. Muitas foram as justificativas dadas pelos professores para não mudarem à abordagem tradicional destinada a história 
dos negros no Brasil: alguns alegaram não terem recebido em sua formação acadêmica inicial um arcabouço de conhecimentos a esse respeito, outros se reportaram a falta de uma formação continuada eficiente para sanar as lacunas relativas a esses saberes, falta de materiais necessários, entre outros motivos foram apresentados. Dos 60 professores, entrevistados por Rocha, 50\% afirmaram que mesmo depois da Lei entrar em vigor eles não trabalham os conteúdos a ela relacionados e $90 \%$ disseram considerar insatisfatória a abordagem feita sobre os negros nos livros didáticos. Várias outras questões foram realizadas por Paixão aos professores, mas não as trataremos aqui. Por hora, nos interessa a presença no mesmo espaço de dois grupos, de posturas antagônicas, um que se coloca no âmbito da ação efetiva, outro que optou pela não atuação. Uma das principais conclusões a que chegou Rocha, para esse segundo grupo, é de que a negação em praticar a Lei, acontece em meio a um conflito pessoal e ideológico, pois os conceitos nos quais o professor acredita está em contradição com o que está sendo prescrito, por meio da legislação, para que ele realize. Diante disso, eles se mantém firmes em suas convicções negando-se a rever suas posturas, ainda que não o façam abertamente. Sob a alegação da existência de um grande número de dificultadores para implantarem a proposta, fazem da inércia sua principal resposta ao descontentamento que sentem em relação as propostas da lei. Superar essas dificuldades pode significar um longo processo de enfrentamentos:

[...] Estas dificuldades têm sido apontadas em quase todos os debates sobre o tema que o autor desse artigo tem participado. No entanto, em que pese a concretude das razões apontadas acima, o entendimento presente nesse artigo é de que, uma das principais dificuldades a ser superada para a efetivação da Lei $10639 / 03$ é o fato de as construções ideológicas sustentadoras do racismo brasileiro estarem presentes, ainda hoje, nos educadores, nos gestores educacionais, e no conjunto da sociedade brasileira. Estas, criadas no passado para a justificação da escravização de africanos e para a naturalização das desigualdades, trazem reflexos muito fortes para a cultura da escola. Este dado parece ser fundamental para qualquer propositura que tenha como objetivo fazer com que a escola possa ser um espaço privilegiado para o enfrentamento ao preconceito, ao racismo e às desigualdades sociais e raciais presentes em nosso país. Nesse sentido, a efetivação da nova legislação precisa ter 
como horizonte um enfrentamento contraideológico. (ROCHA, 2009, p.49-50)

Ainda nos utilizando da pesquisa de Rocha, ele revela que na escola pesquisada existe um grupo de professores empenhados em implementar as propostas da legislação. Sob a ótica da discussão currículo oficial/ currículo real, a decisão desses professores em realizar esse trabalho, funciona como elemento de validação da política curricular nacional. No entanto, nas práticas de sala de aula, novos contextos poderão ser produzidos a partir dessa validação, pois mesmo ela não está isenta apropriações adequadas a cada realidade, concordando com Silva novas identidades e sujeitos podem ser forjados quando ocorre a implementação de uma nova política curricular:

Em um outro nível, enfim, a política curricular, agora já
transformada em currículo, tem efeitos na sala de aula. Ela
define os papéis de professores e de alunos e suas relações,
redistribuindo funções de autoridade e de iniciativa. Ela
determina o que passa por conhecimento válido e por formas
válidas de verificar sua aquisição. O currículo desloca certos
procedimentos e concepções epistemológicas, colocando
outros em seu lugar. A política curricular, metamorfoseada em
currículo, efetua, enfim, um processo de inclusão de certos
saberes e de certos indivíduos, excluindo outros. [...] O
currículo estabelece diferenças, constrói hierarquias, produz
identidades. (SILVA, 2001, p. 11-2)

A partir da dessa pesquisa é possível inferir algumas constatações: primeiramente, os significados que os professores encontram em ensinar ou não um conteúdo diferem muito entre si. Em segundo lugar, o que torna legítimo retirar o currículo da esfera do prescrito para o realizado pode ser, em determinadas situações, uma questão pessoal. Por fim, constatamos que os enfrentamentos são inevitáveis, assim como as resistências e suas estratégias; contudo eles são, muitas vezes, silenciosos. Essa cultura da adoção de estratégias e táticas de resistências silenciosas impede-nos de, pensando estritamente no caso da Lei 10639, detectar onde estão problemas e de propor soluções pertinentes. O silêncio e a ausência de indagação geram a falsa impressão de concordância. Cabe ressaltar também, que o silêncio dos educadores em relação ao seu 
descontentamento com a Lei, pode ser a resposta ao desinteresse dos agentes responsáveis, que elaboram a legislação e a aprovam e não oferecem suporte para que se realize, repetimos novamente que não basta editar uma lei para que mudanças ocorram, não sendo oferecido um suporte material e formativo adequados, os formuladores da Lei delegam a ela a mera função formal e normativa.

Respeitada as especificidades, há o risco de se repetir o desfecho de propostas curriculares anteriores, como a que se deu na última década dos anos noventa, do século passado. Naquele momento, segundo Monteiro, instâncias governamentais e educadores se colocaram em campos opostos e se acusaram mutuamente, os educadores sentiam-se compelidos a serem meros aplicadores de um novo currículo oficial, o resultado foi que:

\begin{abstract}
Essa política acabou por gerar um impasse e grande perplexidade, ao se verificar que os resultados esperados não se concretizavam. Cada vez mais o currículo oficial assumia um caráter prescritivo, e o meio educacional se mostrava refém de um "diálogo surdo". Por um lado, os dirigentes questionavam as escolas e seus professores por não seguirem devidamente as políticas oficiais; por outro, os professores criticavam os governos por formularem políticas que as escolas não conseguiam implantar. (MONTEIRO, 2007, p.178)
\end{abstract}

Diálogo surdo, essa denominação sozinha não esclarece toda nossa problemática, e cremos ser complementar a esse diálogo surdo um pensamento mudo. Um meio para resolver esses impasses passa pela compreensão, de ambos, do que são as políticas curriculares, independente de quais sejam, e a não negação da existência do outro na construção do processo educacional. Esse outro do universo educacional é múltiplo e complexo. Nesse sentido vejamos o que diz Lopes sobre as políticas curriculares:

As políticas curriculares são processos de negociação complexos, nos quais momentos como a produção dos dispositivos legais, a produção dos documentos curriculares e o trabalho dos professores devem ser entendidos como associados. Os textos produzidos nesses momentos, sejam eles registrados na forma escrita ou não, não são fechados 
nem têm sentidos fixos e claros. (LOPES apud MONTEIRO, 2007, p.178)

O grande problema das políticas curriculares é estarem alicerçadas em premissas sempre impositivas e arbitrárias e, portanto carecerem de ressalvas ou, algumas vezes de rechaçamentos. Por causa dessa mesma premissa, a Lei no 10639 ao chegar ao sistema educacional já sofreu um pré-julgamento, dada a sua natureza. Pensar em argumentos favoráveis, que possam reverter esse quadro, passa pela criação de um conjunto defensivo capaz de despertar empatia para com a mesma, o que não é tranquilo, pois não é rara a criação de leis descabidas, teme-se que um precedente se crie partindo defesa. Criar um diálogo que possa levar ao entendimento de que no caso dessa Lei, estão envolvidas outras questões além das curriculares, motivo pelo qual seria interessante validá-la, requer cuidados e conhecimento das inúmeras dimensões envolvidas inclusive, da possibilidade de pouco empenho governamental em efetivá-la, haja vista a carência suportes eficientes e acessíveis àqueles que desenvolvem os conteúdos nas salas de aula.

Algumas indagações surgem no momento de efetivar as propostas da Lei, como se trata de um conteúdo novo, ausente da formação acadêmica de inúmeros professores, e ao qual outros não tiveram acesso em cursos de formação continuada ou através de outros materiais pedagógicos apropriados, o que é necessário à realização do ensino de história da África? Quais quesitos um professor precisa reunir objetivando uma aprendizagem significativa? Weddeburn elenca três pré-requisitos necessários ao ensino de história da África:

Levando em conta tudo o que precede, os estudos sobre a história da África, especificamente no Brasil, deverão almejar a conjunção de três fatores essenciais: uma alta sensibilidade empática para com a experiência histórica dos povos africanos; uma constante preocupação pela atualização e renovação do conhecimento baseado nas novas descobertas científicas, e uma interdisciplinaridade capaz de entrecruzar os dados mais variados dos diferentes horizontes do conhecimento atual para se chegar a conclusões que sejam rigorosamente compatíveis com a verdade. (WEDDEBURN, 2005, p.34) 
Ora, esses pré-requisitos encontram legitimidade na Lei, mas são construídos na prática cotidiana e para tanto necessitam serem apropriados e entendidos por aqueles que dele farão uso, e nenhuma lei realiza essa tarefa. Para que esses quesitos se concretizem Moore adota a tese da adoção de uma pedagogia empática, segundo ele esse processo poderia se construir, a princípio, pela organização de "oficinas de formação de agentes multiplicadores", escolhidos entre os diversos professores das humanidades e não apenas os de história. A ausência dessa empatia, não impossibilita o ensino de história da África, mas o debilita. Nessa perspectiva empática, o autor chama atenção para os velhos e novos problemas que os professores encontrarão no ensino da história africana:

O docente incumbido da missão de ensino da matéria africana se verá obrigado durante longo tempo a demolir os estereótipos e preconceitos que povoam essa matéria. Também terá de se defrontar com os novos desdobramentos da visão hegemônica mundial que se manifesta através das novas ideias que legitimam e sustentam os velhos preconceitos. (MOORE, 2005, p. 33)

Embora, a ideia de missão seja algo que não defenderemos nesse artigo, concordamos que faz parte do trabalho do professor atuar na desconstrução de estereótipos e preconceitos relacionados ao ensino da história da África e dos afrodescendentes, e não é um trabalho simples. A ideia de uma pedagogia empática é importante porque convida o professor a se colocar no lugar do outro e despertar nos alunos o interesse em fazer o mesmo, criando essa empatia com o passado e o presente africanos, que poderá a médio e longo prazo gerar um aprendizado significativo, despido de preconceitos e imbuído de um sentimento de naturalidade no trato com esse conteúdo. A importância no processo ensino aprendizagem, desse conteúdo, se equivale a dos demais conteúdos programáticos. O ensino de História da África carece de ser compreendido como necessário, independente da existência de uma legislação que o obrigue, abandonar a visão de que ele faz parte de uma formação complementar pode ser um primeiro passo rumo a essa naturalização, estamos de acordo com Lima e Souza Neto quando diz: 
O Ensino de uma História da África - ao nosso ver - ultrapassa as determinações de Leis obrigatórias, é mister que ela responda as perspectivas de um Professor de história no momento que este se habilita à compreensão e análise da humanidade em sua trajetória no tempo. Propor um ensino a partir dos estudos "clássicos" e ou antigos não apenas por cumprimento de uma Lei, mas para fazer uma ponte de comunicação entre o passado e o presente, uma vez que o passado comunica o presente, o presente dialoga com 0 passado, fazendo com que a árdua função de um historiador recubra-se de significados e de sentidos. Neste caso um estudo da história da África se justifica por si só como uma responsabilidade designada (LIMA e SOUZA NETO, s/d, p.3)

Essa transformação conceitual ainda é um processo em construção, e o próprio caminho, que deverá ser percorrido para que ela assuma contornos nítidos está se fazendo nas práticas cotidianas. Quando e se esse novo currículo for admitido como sendo sim político, mas também cultural e social, novos significados lhe serão atribuídos, porque ainda que haja diferenças no espaço e nas práticas que produzem os dois, de acordo com Silva, o currículo também é um campo de produção e de criação de significado, pois:

[...] Mesmo que apareça em nossa frente como um produto acabado, como uma matéria inerte, o currículo, como outros conjuntos de matéria significante, é submetido a um novo trabalho de significação, que só pode ser, outra vez, realizado no contexto de relações sociais. [...]. (SILVA, 2001, p.22)

Dentro do contexto escolar enquanto esse novo currículo não adquire significado a Lei 10639/03 será apenas indicações, o trabalho de significação passa pela discussão e compreensão de sua necessidade ou não.

\section{Considerações Finais}

Mudanças curriculares não deveriam acontecer sem uma ampla participação de todos que a posteriori se incumbirão de exercê-las, no entanto seria ingênuo crer na anuência e no consenso irrestrito produto de 
uma maciça presença das partes, fato, aliás, que seria salutar para uma discussão democrática. A diversidade de opiniões é característica inerente as práticas educacionais e aos educadores sendo ótimo que assim o seja. As contradições podem se tornar um problema quando, e se, representam um empasse, frente ao qual não se consegue avançar, isso pode impedir que novas propostas de inserção social e cultural se desenvolvam. É impossível evitar que haja relutância em aceitar a leis como a n¹0639, devido ao seu caráter impositivo. No entanto, em determinadas situações, a ausência de consenso e a não unanimidade paralisam o processo de avanços importantes, ainda que seja das discussões. Não é nosso objetivo negar o caráter o prescritivo e impositivo da Lei no 10639/03 ou de qualquer outra legislação, sejam as que objetivam reformar o currículo escolar, sejam aquelas que alteram uma lei de transito, por exemplo, contudo, entendemos que, às vezes, esse é o caminho inicial a ser trilhado. Também não se trata de atribuir a uma lei poderes capazes reverter um quadro estabelecido há anos na sociedade e sim de visualizar possibilidades, a partir das discussões que a lei poderá suscitar. A adoção de Leis como a 10639/03 e de outras medidas afirmativas, como a política de cotas para negros em universidades, provocam acaloradas discussões contra e prol a suas implementações, muitos não aceitam que elas visam a construção de uma sociedade mais igualitária. Este último grupo coloca questões acerca de:

[...] se as cotas ferem ou não o princípio de igualdade perseguido desde a época moderna e consolidado na legislação atual, cujo principal exemplo seria a própria Constituição Brasileira; se as cotas ferem o princípio do mérito individual e qual o lugar deste princípio numa sociedade mais justa e democrática; sobre as dificuldades de se definir os beneficiários dessa política em um país tão miscigenado como o nosso; [...] uma das questões centrais gira em torno da polêmica entre cotas raciais ou cotas sociais, que levam a discussão sobre justiça social e inclusão de outros grupos marginalizados (os brancos pobres, indígenas, etc). (SANTOS e SIMAN, 2008, p. 99).

Para esse grupo as questões de desigualdade no Brasil são de natureza social e não racial, portanto as correções se fariam, a partir, de 
uma sociedade mais justa socialmente. Em geral, os partidários dessa visão defendem a prerrogativa de que uma educação de boa qualidade para todos seria o meio de promover a inclusão daqueles ainda alijados dos direitos sociais básicos. Talvez, essa afirmação possa ser verdadeira e vamos aceitar que o seja. Contudo, no século XXI, não é possível a concepção de uma educação boa e de qualidade que não seja inclusiva, na qual as experiências humanas presentes no tempo e relacionadas aos diferentes indivíduos não se faça presentes. Os partícipes do processo de ensinoaprendizagem precisam se ver contemplados naquilo que lhes é ensinado, somente assim poderão encontrar significado no aprendido e localizarão seu lugar dentro dessa história universal.

A Lei no 10639/03 é uma tentativa de inserção no currículo real da trajetória histórica dos antepassados de parte considerável da população. Encarar a Lei apenas sob os aspectos curriculares impositivos pode ser reducionismo porque corre-se o risco de deixar escapar as particularidades que a envolve ou deveria envolver: levantar discussões sobre a problemática que circunda a história da população negra brasileira, as questões de preconceito, de discriminação e de exclusão, que sim são sociais, mas também raciais. O fato de não ter havido no Brasil uma política de apartheid não é sinônimo de ausência dos problemas citados. Educar para a superação e, principalmente para inclusão das diferenças, é uma obrigação de toda sociedade, por conseguinte da escola, carecemos, no entanto, de uma discussão mais ampla e de uma formação mais efetiva e eficaz dos educadores encarregados de realizá-la, é preciso que sejam disponibilizados meios materiais e formativos aos professores, evitando análises superficiais ou reforço de antigos preconceitos ou estereótipos.

\section{Referências}

CHERVEL, A. História das disciplinas escolares: reflexões sobre um campo de pesquisa. Teoria e Educação, n. 2, 1990.

DE CERTEAU, M. A invenção do cotidiano. Artes de fazer. Trad. Ephraim Ferreira Alves, 2 ed., Petrópolis, RJ: Vozes, 1994. 
FERNANDES, José Ricardo Oriá. Ensino de história e diversidade cultural: Desafios e possibilidades. Cad. Cedes, Campinas, v. 25, n. 67, set./dez. 2005.

GOODSON, I. F. Currículo: Teoria e História. Trad. Atílio Brunetta Petrópolis: Vozes, 2005.

LIMA, S. M. Z; SOUZA NETO J. M. G. de. A Literatura, fonte primária para o Ensino de História da África. Disponível em:

www.anpuhpb.org/anais xiii eeph/textos. Acesso em 30 jun. 2011.

MONTEIRO, A. M.; GASPARELlo, A.; MAGAlHÃES, M. de S. Ensino de História: sujeitos, saberes e práticas. Rio de Janeiro: Mauad, 2007.

MOREIRA, J. H. S e PEREIRA, J. S. Do conteúdo a recepção: o guia do livro didático de história (2005/2008). História \& Ensino: Revista do Laboratório de Ensino de História/UEL, v. 15, Londrina, 2009,.

MUNAKATA, K. O livro didático e o professor: entre a ortodoxia e a apropriação. In MONTEIRO, Ana Maria et. al. (Org.). Ensino de História: sujeitos, saberes e práticas. s/ed. Rio de Janeiro: Faperj/Mauad, 2007.

ROCHA, L. C. P. da. Lei 10639/03: Desafios e perspectivas para a implemantação dos conteúdos afro-brasileiros nas escolas. In SOUZA, M.H.V (Org.). Relações raciais no cotidiano escolar: diálogos com a lei 10639/03. Rio de Janeiro: Rovelle, 2009.

SACRISTÁN, J.G. e GOMES, A.I.P. Compreender e transformar o ensino. Porto Alegre, Artmed, 2000.

SANTOS, L. dos; SIMAN, L. M. de C. O que dizem os professores sobre o sistema de cotas para negros nas universidades públicas. História e Ensino: Revista do Laboratória de Ensino de História/UEL, v. 14., Londrina, 2008,

TARDIF, M e RAYMOND, D. "Saberes, tempo e aprendizagem do trabalho no magistério. Educação e Sociedade, ano XXI, n073, Dez/2000.

WEDDEBURN, M. C. Novas bases para o ensino da história da África no Brasil. In Educação anti-racista: caminhos abertos pela Lei Federal no. 10.639/03. Brasília: Edições MEC/B1D/UNESCO, 2005. 